\title{
Prevalence of Thyroid Defects in Diyala, Iraq
}

\author{
Mohammed Mohammud Habash \\ Assistant Professor in General Surgery, College of Medicine, Diyala University, Diyala, Iraq
}

\begin{abstract}
Thyroid disorders are associated with the abnormalities occur in thyroid hormone concentration and imbalance in their regulation may causes life threatening diseases. Thus, the present study was planned to establish the prevalence of thyroid defects in Diyala, Iraq due to paucity of information is available in our region. Total 67 subjects in the age range of 20-80 years were recruited in Al - Shafa hospital, Diyala, Iraq, suffering from thyroid disorders or suspected with the symptoms favoring thyroid diseases. Thyroid function test and physical examination were performed. Those who were found alteration in thyroid hormones and presence of nodules, further investigation like FNAC of neck was performed for the diagnosis. Once confirmation of thyroid defect, total thyroidectomy was performed as a first line of treatment and malignancy was confirmed using histopathology analysis. The incidence of thyroid diseases in female (86.57\%) was found to be more than male (13.43\%) and there ratio was 19.3:3. The thyroid defects incident rate was highest in mean 49 years age. Almost $61.2 \%$ patients were found affected by thyroid disorders in this age group. The largest number of patients $(64.18 \%)$ had shown MNG, then other thyroid defects out of which 4 female patients presented very big thyroid multinodular goiter (MNG). Among $43 \mathrm{MNG}$ patients, $86 \%$ patients were female and $4 \%$ were male. Of the 67 cytologically diagnosed cases, $79.10 \%$ cases were found benign cases which are highest among all other types, out of which $91 \%$ cases were female. Among the thyroid disorder burden of thyroid carcinoma is very high and common in the enrolled patients in Diyala, further longitudinal studies are required to explore the prognosis and causes of these thyroid defects in the Iraq.
\end{abstract}

Keywords: Prevalence, thyroid defects, thyroid stimulating hormone, carcinoma

\section{Introduction}

Thyroid diseases also called as endocrine disorders which are common worldwide. Thyroid is a butterfly shaped, small hormone secreting gland weighing approximately $20-25 \mathrm{gms}^{1,2}$. This gland is situated near throat and regulates body metabolism. Thyroid follicles mainly synthesize and secrets about $93 \%$ of thyroxine (T4) and 7\% of Triiodothyronine (T3) hormones ${ }^{3,4}$. While pituitary glands of the brain produce the thyroid stimulating hormone which is another important hormone and play crucial role in stimulation of thyroid to synthesize and release T3 and T4 into the bloodstream ${ }^{2,5}$.

Various thyroidal disorders are associated with the abnormalities occur in thyroid hormone concentration and imbalance in their regulation causes range of disorders from small goiter to life threatening diseases ${ }^{3,6}$. As these hormones play vital role in control of metabolism, growth, menstrual cycles, muscle strength, functioning of vital organs ${ }^{7}$. Overall, they play major role in human life essentially for the development, function of almost all human tissues and regulation of metabolism ${ }^{8,9}$.

Thyroid disorders are mainly caused by having deficiency in iodine. Abnormality in thyroid function and enlargement of the thyroid gland are the major features seen in these disorders ${ }^{10}$. These defects were mostly in the form of lesions which are in the form of inflammatory at origin, congenital malformations, endocrinal, benign and malignant in type ${ }^{11}$. Underactive thyroid symptoms are same in both the genders, fatigue, weight gain, depression, weakness and elevated cholesterol levels ${ }^{12}$. Over secretion and under secretion of thyroid hormones are major disorders named hyperthyroidism and hypothyroidism respectively. These situation leads to thyroid defects which has different indexes and 
indications ${ }^{13}$.

Thyroid defects were reported worldwide in over 110 countries with about 1.6 billion people are at risk as they are from iodine deficient areas. These areas are mostly developing countries like Asia, Africa and Latin America ${ }^{14}$. Earlier studies reported that prevalence of thyroid diseases throughout the world is $25 \%$ in women and $0.6 \%$ in $\operatorname{men}^{15,17}$. Most common found thyroid cancer is multinodular goiter and papillary carcinoma. Prevalence of the thyroid defects depends on some risk factor which includes age, sex, ethnicity, geographical factors, intake of iodine and exposure to the radiations ${ }^{18,20}$. Fine needle aspiration biopsy (FNAC) and ultrasonography are the advance tools to diagnose the cancer in any stage. Initially ultrasonography was performed to follow progression of size of the gland. If thyroid scan shows hyperfunctioning nodules or increase in size of nodule, FNAC will be performed to confirm the malignancy ${ }^{21}$. With advent of ease of diagnosis and convenient medical treatment it offers relative visibility to treat by physician ${ }^{21,22}$. By highlighting the earlier prevalence of thyroid defects and to the best knowledge of author, no study has been conducted in our region to highlight prevailing data on thyroid disorders. There is paucity of the information available in our region, which have looked the incidences of thyroid disorders in patients. Thus, present study was planned to establish the prevalence of thyroid defects in Diyala, Iraq.

\section{Methodology}

The retrospective study was conducted with the prior permission of an ethical committee of $\mathrm{Al}$ - Shafa hospital, Diyala, Iraq during January 2018 to January 2020. The study includes 67 patients of both sexes aged 20 to 80 years and they were divided into 6 groups according to their age. Thyroid function tests were performed to evaluate the levels of thyroid hormones before the surgery of each patient. Patients were confirmed with the findings having swelling on the neck including nodular surface or nodules using available techniques. Total thyroidectomy was performed to as a first line of treatment.
Total thyroidectomy was performed after taking written consent for excision of lymph node. All surgeries were done under general anesthesia by using an Endo tracheal tube. Reverse tredlenberg position (head up) with the extended neck position were given to the patients. The collar incision was used. Upper and lower flaps were placed to retract instead of Joll's retractor. This was done by using cautery (coagulation diathermy). Ligations of middle thyroid veins were done by 1 vicryl or silk followed by ligations of superior thyroid artery and veins. Inferior thyroid vessels were also ligated. During the surgery, redivac drains were used and removed after 2 to 3 days. Second generation cephalosporins antibiotics were given after surgery. Stitches were removed after 5 days. After 1 week after surgery, thyroxine was given.

\section{Statistical Analysis}

The data were represented as the mean. The biochemical estimation was performed in triplicate.

\section{Results}

This paper represents and analyses the clinicopathological data to evaluate the incidence of thyroid defects in patients ( $\mathrm{n}=67,20$ to 80years) of Diyala. Patients were recruited having neck swelling, viewing values of thyroid function test and checking all clinical findings. The incidence of thyroid diseases in female was found $86.57 \%$ and $13.43 \%$ in male patients having sex ratio of female to male 19.3:3. Incident rate of thyroid cancer was found to be highest in women than in men. The minimum age of the patient found having thyroid defect is 20 years, while maximum age in men was 60 years and in female it is 78 years. Thus, total mean age was 49 years suggesting that thyroid defects were incident highest in this age range. The maximum patients were observed in the age, ranges between 31 to 50 years. Almost $61.2 \%$ of patients were found affected by thyroid disorders and female are predominates (Table 1). In the age group 31-40 years, female to male sex ratio was found to be $6: 1$, while in the age group 41-50 years it was found $3: 1$. 
Table 1. Age and sex distribution of patients $(n=67)$ having thyroid disorders

\begin{tabular}{|c|c|c|c|c|}
\hline Age group (Years) & Males & Females & Total cases & Percentage \\
\hline $20-30$ & 0 & 13 & 21 & 13.40 \\
\hline $31-40$ & 3 & 18 & 20 & 29.85 \\
\hline $41-50$ & 5 & 15 & 10 & 14.93 \\
\hline $51-60$ & 1 & 9 & 2 & 0.03 \\
\hline $61-70$ & 0 & 2 & 1 & 0.02 \\
\hline $71-80$ & 9 & 58 & 67 & 100 \\
\hline
\end{tabular}

In our study we have come across number of clinical findings associated with thyroid disorders. Some are listed in the table 2 to get tentative discrimination of type of thyroid defects in patients. These findings were carried out the fine needle aspiration biopsy technique. Among 67 patients $9(13.43 \%)$ cases were found having diffused goiter, $7(0.1 \%)$ was diagnosed with single thyroid nodules and remaining patient were detected with the MNG (Table 2). Largest number of patients (64.18\%) out of total had shown MNG, then other thyroid defects out of which 4 female patients presented very big thyroid multinodular goiter. Among $43 \mathrm{MNG}$ patients, $86 \%$ patients were female and $4 \%$ were male with female to male sex ratio $6.2: 1$.

Table 2. Clinical findings of patients $(n=67)$ having thyroid disorders

\begin{tabular}{|c|c|c|c|c|}
\hline Clinical findings & Males & Females & Total cases & Percentage \\
\hline Diffuse goiter & 1 & 8 & 7 & 13.43 \\
\hline Single thyroid nodule & 0 & 7 & 43 & 0.10 \\
\hline Multiple thyroid nodule & 6 & 37 & 4 & 0.06 \\
\hline Very big thyroid MNG & 0 & 4 & 63 & \\
\hline Total & 7 & 56 & 64.18 \\
\hline
\end{tabular}

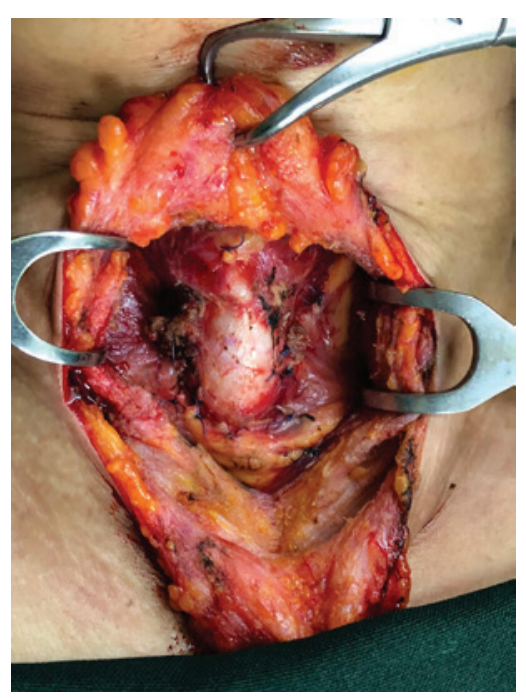

Figure 1. An exposed multinodular gland 
Figure 2. Macroscopic giant nodular goiter

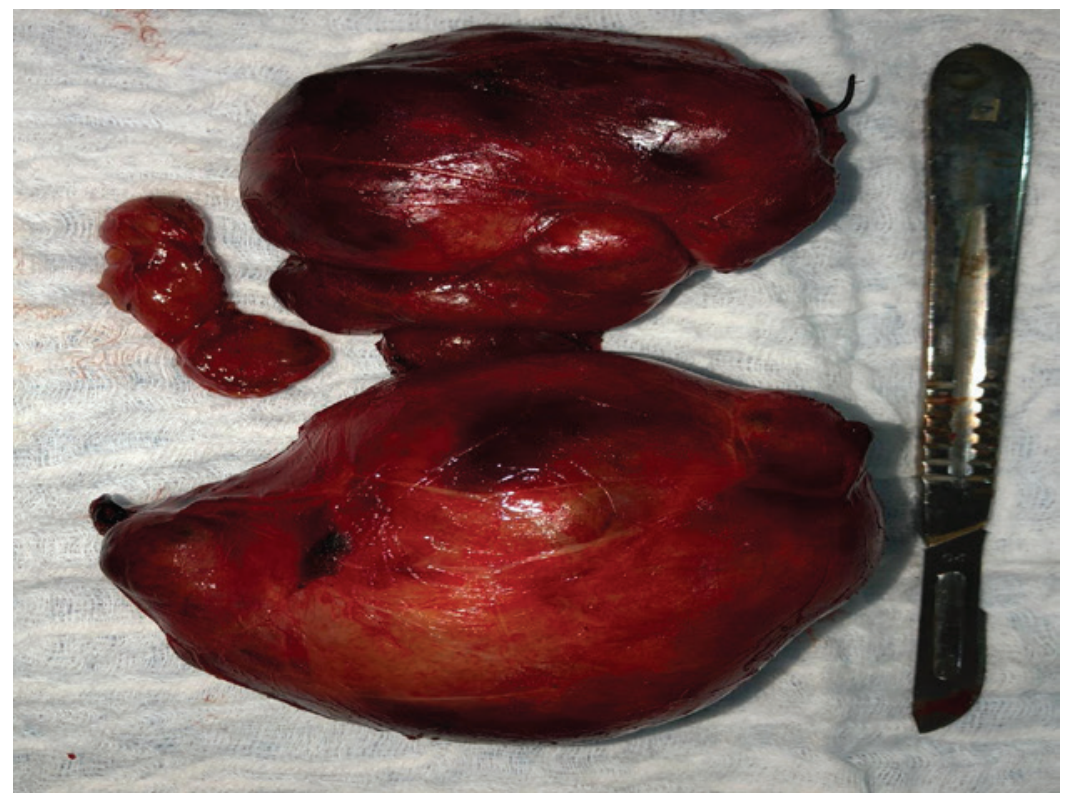

Figure 3. Immediate postoperative incisions

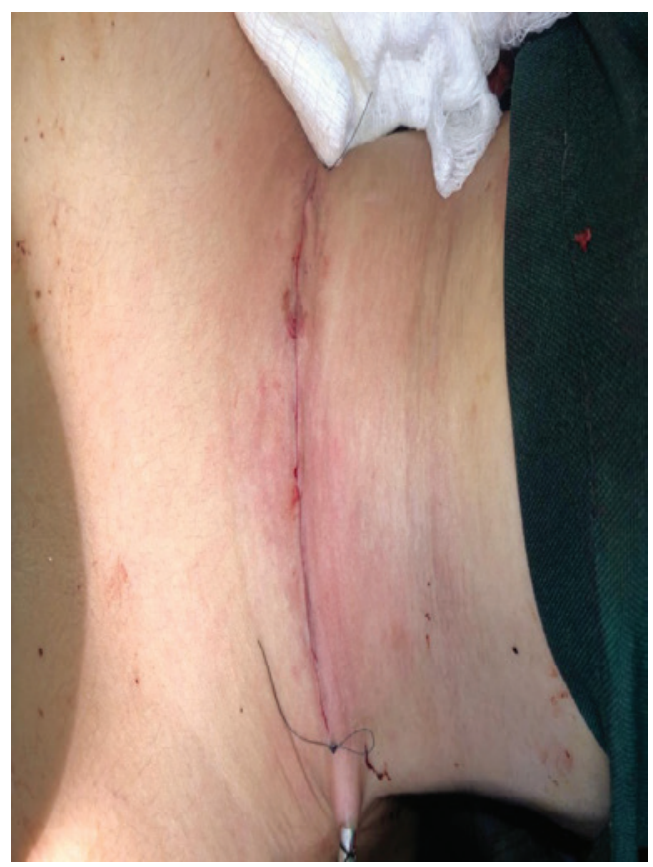

Ten cases were identified with the PTC, 53 were detected having benign nodules and 4 cases having other findings which includes auaplastic carcinoma, and lymphocytic thyroiditis (Table 3). Of the 67 cytologically diagnosed cases, $79.10 \%$ cases were found benign cases, which is highest among all other types, out of which $91 \%$ cases were female. According to our data, prevalence of thyroid carcinoma is highest in female patients than men. 
Table 3. Histopathological analysis of patients having thyroid disorders

\begin{tabular}{|c|c|c|c|c|}
\hline Histology findings & Males & Females & Total cases & Percentage \\
\hline Papillary thyroid carcinoma (PTC) & 4 & 6 & 10 & 14.93 \\
\hline Benign & 5 & 48 & 53 & 79.10 \\
\hline Other & 0 & 4 & 4 & 0.06 \\
\hline Total & 9 & 58 & 67 & 100 \\
\hline
\end{tabular}

In most of the cases, thyroid nodules were multiple and hard in texture. The nodules were variable in size.

\section{Discussion}

Thyroid defect is a silent disease in which symptoms are understated and need critical monitoring ${ }^{12}$. Nowadays, thyroid swelling is the commonest clinical findings found with 4-7\% prevalence in general population. It ranks second position among females in Saudi $\mathrm{Arab}^{23}$. Major cause of these disorders is abnormality in the regulation of thyroid hormones. As these hormones play major roles in metabolism, mental health as well as muscle strength ${ }^{24}$. Earlier clinical survey in India, reported maximum cases of thyroid defects. About 33 lakh adults diagnosed with the abnormalities in the TSH, T3 and T4 hormones, of which $68 \%$ were found normal and $32 \%$ of enrolled population was diagnosed with different kinds of thyroid disorders which includes, hyperthyroidism, thyroid nodules, thyroiditis, goiter and even thyroid cancer ${ }^{22}$.

Based on the morphology, thyroid disorders are divided into tumor and non-tumor diseases. According to literature, causes of these nodule appearances are complex and still underexplored ${ }^{19}$. Neoplastic and nonneoplastic lesions were detected in the diagnosis of thyroid disorder, in order to confirm the malignancy ${ }^{11}$. Majority are non-neoplastic, but malignant were also non avoidable. Simple, accurate, cost effective screening techniques like FNAC or ultrasonography are quick and reliable diagnostic methods used for rapid diagnosis of thyroid defects. Due to this first line of treatment prevalence is underscored providing potential curability ${ }^{25}$. After confirmation, as a first line of treatment among different type of surgeries total thyroidectomy was preferred in case of malignancy. In this technique complete malignant part of the gland was removed to reduce recurrence rate ${ }^{26}$.

Earlier studies proved that age and sex are the associated factors of thyroid defects ${ }^{27}$. In the survey on the diseases in the world, thyroid disorders highlighted with the highest prevalence in which $25 \%$ in females and $0.6 \%$ in males ${ }^{16}$. Many studies have proved that prevalence of thyroid diseases found highest in female than in male at the middle age ${ }^{27-29}$. This data is in accordance with our data where more female patients were diagnosed with the thyroid defects than male count with the ratio 19.3:3. This gender disparity having high prevalence in female is may be associated with estrogen and progesterone ${ }^{16}$. The study carried out in Iraq concluded that female to male ratio diagnosed with hypothyroidism was 1.6:130. Similarly, In Yemen higher incidence of thyroid cancer was detected in female than in males which is 90 and $89.7 \%$, respectively ${ }^{31}$. It was reported that age advances the incidence of thyroid disorders in both genders ${ }^{24}$. In our study mean age of the patient found 49 years while maximum 60 years in male and 78 years in female. However, it was mentioned in the studies that thyroid cancer is common in older patients and having significant morbidity if not treated in early stages ${ }^{24}$.

Before the surgery, we must analyses the clinical findings in which FNAC or ultrasonography was used to evaluate the thyroid gland. In our study, we have found maximum patients diagnosed with the MNG. In the swollen neck we can examine the solitary or multiple 
nodules. In case of MNG, among all, one nodule is clinically dominant in terms of size and functions ${ }^{19}$. It results from the drastic growth and morphological or functional transformation within the thyroid tissue ${ }^{21}$. Our data is well corroborated with the earlier studies which states that MNG has highest, about $4-7 \%$ prevalence worldwide than other thyroid defects ${ }^{32}$. It was stated in the earlier research that according to prevalence and malignancy, patients presenting MNG must undergo surgical process ${ }^{33}$. All the enrolled patients underwent to the total thyroidectomy to get rid from the malignancy found in clinical findings. Malignancy was confirmed by observing histopathology reports in the patients. Nodules can be of non-neoplastic which includes inflammatory and hyperplastic nodules and neoplastic which includes benign and malignant. Benign nodules include adenomas, while malignant includes carcinomas (papillary and follicular) ${ }^{19}$. It was also reported that PTC was detected mostly in patients diagnosed with benign thyroid goiter ${ }^{34}$. In the present study, PTC was diagnosed in $14.9 \%$ of patients while highest $(79.10 \%)$ patients were diagnosed benign in appearance. These results support the earlier studies which states that, thyroid carcinoma has highest prevalence among the malignant diseases. Among these PTC accounts highest burden, almost $80 \%$ than others ${ }^{35,36}$. Overall, in the study highest prevalence is observed in female patients having multiple nodules and confirmed the malignancy with the benign carcinoma after histopathology study through total thyroidectomy.

\section{Conclusion}

According to our study, about $86.57 \%$ women suffered with various forms of thyroid defects with mean age of 49years. Symptoms are similar in both male and female, but prevalence was found highest in females. The high incidence of thyroid disorder was found Diyala and the risk factors like gender, age and associated malignancy. Benign and papillary carcinoma were common than the non-neoplastic lesions. Present study endorsed the early detection and prevention of these diseases at its early stage by spreading awareness of the diseases and their determinants to underscore the prevalence as well as helps to avoid complications. Further, this study recommends community-based study with larger sample size. The longitudinal studies are required to explore the prognosis and causes of these thyroid defects in the Iraq.

Conflict of Interest: There is no conflict of interest regarding this research paper

\section{Source of Funding: Self}

Ethical Clearance: The research work proves in novelty of the proposed work

\section{References}

1. Chandrasoma P, Taylor CR. Concise pathology, $2^{\text {nd }}$ Ed. 1997, Pp:626-845, Prentice Hall International Inc.

2. Marieb E, Hoehn K. Regulation and integration of the body. The endocrine system. Human anatomy and physiology. 7th edition. San Francisco, CA: Pearson Education Inc. 2007: 620-625.

3. Guyton AC, Hall TE. Text book of medical Physiology. $9^{\text {th }}$ Ed. 1996, Pp: 945-946; W.B. Saunders Company.

4. Al-Shahrani AS, El-Metwally A, Ai-Surimi K, Salih SB, Saleh Y, Al-Shehri A, Ali A. The epidemiology of thyroid diseases in the Arab world: A systematic review. J. Public Health Epidemiol. 2016; 8(2):1727.

5. Maurya H. Thyroid Function Disorders among the Indian Population. Annals of Thyroid Res. 2008; 4(3):172-173.

6. Ratini M. Understanding thyroid problems - the Basics: Women's Health. WebMD Medical Reference, 2015. WebMD, LLC.

7. Jameson J, Weetman A, Fauci A, Braunwald E, Kasper D, Hauser S. Disorders of the thyroid gland. Harrison's principles of internal medicine. $17^{\text {th }}$ edition. USA: The McGraw Hill Companies Inc. 2008: 2224-2247.

8. Medici M, Deure WM, Verbiest M, Vermeulen SH, Hansen PS, Kiemeney LA, Hermus RM, Breteler MM, Hofman A, Hegedus L, Kyvik KO, Heijer M, Uitterlinden AG, Visser TJ, Peeters RP. A largescale association analysis of 68 thyroid hormone pathway genes with serum TSH and FT4 levels. Eur J Endocrinol. 2011; 164(5):781-788. 
9. Peeters RP, Van der Deure WM, Visser TJ. Genetic variation in thyroid hormone pathway genes; polymorphisms in the TSH receptor and the iodothyronine deiodinases. Eur J Endocrinol. 2006; 155(5):655-62.

10. Zimmerman MB. Iodine deficiency. Endocr. Rev. 2009; 30:376-408.

11. Kumbhar S, Kanetkar S, Mane A, Khurana C, Sharma N. Clinicopathological study of thyroid lesions. IJBAMR. 2018, 7(3):80-97.

12. Braverman LE, Utiger RD, Eds. Werner \& Ingbar's The thyroid: A fundamental and clinical text. 8th edition. Philadelphia, Pa: Lippincott, Williams \& Wilkins. 2000: 837-838.

13. Khan A, Khan MM, Akhtar S. Thyroid disorders, etiology and prevalence. J. Med. Sci. 2002; 2(2): 89-94.

14. WHO, 1996. Universal salt iodization works quality control and monitoring are critical elements for success. Press release, WHO/52.

15. Hitman S, Kelly FC. Prevalence of congenital hypothyroidism. Indian J Endocrinol. 1999; 45(4):245-249.

16. Nimmy NJ, Aneesh PM, Marmadha MP, Udupi RH, Binu KM. A Survey on the prevalence of thyroid disorder induced by demography and food habits in south indian population. IJOPP. 2012; $5(2): 49-52$.

17. Dal Maso L, Lise M, Zambon P, Falcini F, Crocetti E, Serraino D, Cirilli C, Zanetti R, Vercelli M, Ferretti S, Stracci F, De Lisi V, Busco S, Tagliabue G, Budroni M, Tumino R, Giacomin A, Franceschi S. Incidence of thyroid cancer in Italy, 1991-2005: time trends and age-period-cohort effects. Ann. Oncol. 2011; 22(4):957-963.

18. Davies M., John R. Factors affecting thyroidism in Americans. Indian J Physiol Pharmacol. 1998; 42(2):58-62.

19. Sulejmanovic M, Cickusic AJ, Salkic S, Bousbija FM. Annual incidence of thyroid disease in patients who first time visit department for thyroid diseases in Tuzla canton. Materia Socio Medica. 2019;31(2):130-134.

20. Chaturvedi S., Sanjay M., Gupta P. Assessment of iodine induced Disorders. J Indian Med Assoc.,
2006;94:127-135.

21. Leung AM., Mestman JH. Disorders of the thyroid gland. Global library of women's medicine. 2015.

22. Unnikrishnan AG, Menon UV. Thyroid disorders in India: An epidemiological perspective. Indian J Endocrinol Metab, 2011; 15:78-81.

23. Sawka AM, Brierley JD, Tsang RW, Thabane L, Rotstein L, Gafni A, Straus S, Goldstein DP. An updated systematic review and commentary examining the effectiveness of radioactive iodine remnant ablation in well-differentiated thyroid cancer. Endocrinol. Metab. Clin. North Am. 2008; 37(2):457-480.

24. Madhuvan HS, Ravishankar SN, Reddy S, Chandrashekhara P, Nikhil D. A prospective study of thyroid - dysfunction in elderly patients and its clinical correlation. Arch. Med. 2013; 5(2):1-11.

25. Datta RV, Petrelli NJ, Ramzy J. Evaluation and management of incidentally discovered thyroid nodules. Surg. Oncol. 2006; 15:33-42.

26. Athavale VS, Thakkar SM, Gope DD, Tulsian AR, Sree Kumar B, Gogineni JC. A clinicopathological study of multinodular goitre. Int Surg J. 2019, 6(3):892-897.

27. Pal R, Kar S, Forhad A, Sengupta S, Pal S. Fine needle aspiration cytology as the primary diagnostic tool in thyroid enlargement. J Nat Sci Biol Med. 2011; 2(1):113-118.

28. Gupta M., Khushbu T. Correlation of fine needle aspiration cytology with histopathological diagnosis in thyroid lesions. EJPMR, 2016; 3(10):218-221.

29. Khatib Y, Mulla A, Richa D, Patel Momin E, Vinod G, Khade A. Classification of thyroid FNA smears into bethesda categories and their correlation with thyroid function tests. Sch. J. Appl. Med. Sci. 2016; 4(3):916-923.

30. Nasheiti N. Childhood hypothyroidism in Iraq: a retrospective study. Int J Endocrinol Metab. 2005; 3(3):136-139.

31. Abdulmughni YA, Al-Hureibi MA, Al-Hureibi KA, Ghafoor MA, Al-Wadan AH, Al-Hureibi YA. Thyroid cancer in Yemen. Saudi Med J. 2004; 25(1):55-59.

32. Wiest PW, Hartshorne MF, Inskip PD, Crooks LA, Vela BS, Telepak RJ, Williamson MR, Blumhardt 
R, Baoman JM, Tekkel M. Thyroid palpation versus high-resolution thyroid ultrasonography in the detection of nodules. J Ultrasound Med. 1998; 17(8):487-496.

33. Yong JS, Loh KS, Petersson BF, Thong M. Multinodular goitre: a study of malignancy risk in nondominant nodules. Ear Nose Throat J. 2017; 336-342.

34. Abdullah MI, Junit SM, Ng KL, Jayapalan JJ, Karikalan B, Hashim OH. Papillary thyroid cancer: genetic alterations and molecular biomarker investigations. Int J Med Sci. 2019; 16:450-461.

35. Brown RL, De Souza JA, Cohen EE. Thyroid cancer: burden of illness and management of disease. J. Cancer. 2011; 2:193-199.

36. Mazzaferri EL. Long-term outcome of patients with differentiated thyroid carcinoma: effect of therapy. Endocr. Pract. 2000; 6:469-476. 